\title{
Early postoperative evaluation of secondary bone grafting into the alveolar cleft and its effects on subsequent orthodontic treatment
}

\author{
Takuya Seike"), Ichiro Hashimoto", Kazuya Matsumoto²), Eiji Tanaka ${ }^{3)}$, and \\ Hideki Nakanishi" \\ ${ }^{1}$ Department of Plastic and Reconstructive Surgery, Institute of Health Biosciences, the University \\ of Tokushima Graduate School ; ${ }^{2}$ Department of Plastic, Reconstructive and Aesthetic Surgery, Taoka \\ Hospital, Tokushima, Japan; and ${ }^{3}$ Department of Orthodontics and Dentofacial Orthopedics, Institute \\ of Health Biosciences, the University of Tokushima Graduate School, Tokushima, Japan
}

\begin{abstract}
Background : Alveolar bone grafting is a standard procedure used to achieve good occlusion for both functional and aesthetic purposes in patients with cleft lip and palate. At the past, main methods used to evaluate bone bridge formation after bone grafting are radiographs, such as dental, occlusal, and panoramic. Purpose : To evaluate bone bridge both qualitatively and quantitatively, we used CT scans (conventional and QCT). Quantitative computed tomography (QCT) has previously been used for measuring bone mineral density of the lumbar vertebrae. Patients and methods : The study comprised 26 male and 15 female patients who underwent alveolar bone grafting. We analyzed bone bridge with regard to four factors : marginal bone level, vertical height, anteroposterior bone width and bone mineral density using dental radiographs, and CT scans such as conventional and QCT. The clinical results of orthodontic treatment were evaluated more than 2 years postoperatively. Results : Orthodontic treatment was considered to be successful when the bone bridge satisfied the following criteria : marginal bone level $\geqq 3$, vertical height $\geqq 6.5 \mathrm{~mm}$, anteroposterior bone width $\geqq 5 \mathrm{~mm}$, and bone mineral density $<350$ $\mathrm{mg} \mathrm{Ca}_{5}\left(\mathrm{PO}_{4}\right) \mathrm{OH} / \mathrm{mL}$. Conclusion : we could predict the prognosis of patients' orthodontic treatment in early stage after bone grafting. J. Med. Invest. 59 : 152-165, February, 2012
\end{abstract}

Keywords : alveolar cleft, bone graft, bone bridge, QCT, early evaluation

\section{INTRODUCTION}

Secondary alveolar bone grafting has become a standard treatment for patients with cleft lip and palate (1). The objectives of this surgical procedure

Received for publication November 28, 2011 ; accepted December 27, 2011.

Address correspondence and reprint requests to Takuya Seike, M.D., Department of Plastic and Reconstructive surgery, Institute of Health Biosciences, the University of Tokushima Graduate School, Kuramoto-cho, Tokushima 770-8503, Japan and Fax : +81-88-633-7297. have been well documented (2). One of the main objectives is bone formation that allows orthodontic movement of teeth into previous cleft sites. In order to meet this objective, a sufficient height and volume of the grafted bone must be available. Postoperative bone formation in alveolar clefts has been evaluated by dental, occlusal, and panoramic radiographs. However, these conventional radiographs have been shown to have a number of limiting factors, such as distortion, limited number of reliable landmarks, and superimposing structures (3). To resolve these 
problems, computed tomography (CT) has recently been used to evaluate bone graft, and it has been shown to enable longitudinal changes in the volume of the grafted bone to be evaluated $(3,4)$.

To provide a reference in the CT images, we placed a phantom near the face of the patient to include both the phantom and grafted area together in the same field (5). It is then possible to calculate the bone mineral density of the grafted area by comparing the CT number of the area with that of the phantom. This method, known as quantitative computed tomography (QCT), has been used for measuring bone mineral density of lumbar vertebrae $(6$, 7). However, it has not been used to evaluate the bone grafts in patients who have been treated for alveolar cleft.

\section{PURPOSE OF THIS STUDY}

It is important to postoperatively analyze the outcome of bone grafting as early as possible, because the age suitable for bone grafting and orthodontic procedures is limited. Early evaluation can lead to immediate restart of any interrupted orthodontic treatment or re-operation for bone grafting, if necessary. The outcome of the alveolar bone grafting has often been evaluated using dental radiographs, obtained after a relatively short follow-up period $(8,9)$. Long-term assessment is necessary to confirm the success of orthodontic treatment, which is the purpose of alveolar bone grafting. It has been shown that the clinical outcome of orthodontic treatment after long-term follow-up differs from that estimated from postoperative images $(10,11)$.

We used dental radiographs and QCT to examine patients who had undergone alveolar bone grafting. We investigated whether QCT was able to contribute to accurately assess the results of bone grafting, and compared the efficacy of QCT with that of dental radiographs and simple $\mathrm{CT}$.

\section{PATIENTS AND METHODS}

Patients : We performed 49 secondary bone grafting procedures in 41 patients with cleft lip and/or palate at the Tokushima University Hospital from 1998 to 2001 . The patients (26 boys and 15 girls) consisted of 15 unilateral cleft lip and palate patients (UCLP), 10 bilateral cleft lip and palate patients (BCLP), 14 unilateral cleft lip and alveolus patients (UCLA) and 2 bilateral cleft lip and alveolus patients (BCLA). The age of patients ranged from 6 to 15 years (mean : 9.8) (Table 1 ).

Operation method : The grafts used cancellous bone from the iliac crest, following the procedures described for the gingival mucoperiosteal flap method by Boyne and Hall $(8,9)$.

Measurements : All patients underwent dental radiographs and QCT three months after alveolar bone grafting. Marginal bone level of the bone bridge was measured on the teeth adjacent to the cleft, shortest vertical length of bone bridge on the dental radiographs, and shortest anteroposterior bone width was measured on CT imaging. The details are shown in the following.

\section{Marginal bone level}

We classified the lowest marginal bone level of the alveolar bone bridge into 5 levels following the classification described by Enemark et al. (11). We traced the outline of the central incisor in the proximal position of the alveolar cleft, canine in the distal position, and alveolar bone including clefts on the intraoral dental radiograph. Using these landmarks the following points were described (Figure 1) :

Point $\mathrm{O}$ : Midpoint of the boundary between cementum and enamel of the central incisor

Point O' : Midpoint of the boundary between cementum and enamel of the canine

Line $r$ : The line passed which passed in point $O$ and point $\mathrm{O}$ '

Line $r$ was designated as the base line.

The length from point $\mathrm{O}$ to the root tip of the lateral incisor was divided into four quarters, and 3 lines were established parallel with Line r. These 3 lines were designated as Line 1 , Line $m$, and Line $n$, in order of their position from the direction of the crown toward the lateral incisor.

We evaluated the position of the lowest marginal bone level of the bone bridge using a 5-point scoring system as follows :

Score 4 : Lowest marginal bone level of the bone bridge between Line $r$ and Line 1

Score 3 : Lowest marginal bone level of the bone bridge between Line 1 and Line $m$

Score 2 : Lowest marginal bone level of the bone bridge between Line $m$ and Line $n$

Score 1 : Lowest marginal bone level of the bone bridge below Line $n$

Score 0 : No bone formation 
Table 1 : Demographic and clinical characteristics of the subjects

\begin{tabular}{|c|c|c|c|c|c|c|}
\hline Case Number & Age of Graft(y) & gender & Cleft Type & Side of grafting & Presence of Fistula & eruptive stage of canine \\
\hline 1 & 12 & $\mathrm{~F}$ & UCLAP & $\mathrm{Lt}$ & - & Erupted \\
\hline 2 & 9 & M & UCLAP & $\mathrm{Lt}$ & + & Unerupted \\
\hline 3 & 12 & M & BCLAP & $\mathrm{Lt}$ & - & Erupted \\
\hline 4 & 11 & M & UCLA & Rt & - & Erupted \\
\hline 5 & 10 & $\mathrm{~F}$ & BCLAP & Rt & - & Unerupted \\
\hline 6 & 10 & M & BCLAP & $\mathrm{Lt}$ & - & Unerupted \\
\hline 7 & 10 & $\mathrm{~F}$ & BCLAP & Rt & - & Unerupted \\
\hline 8 & 8 & $\mathrm{~F}$ & UCLA & Rt & - & Unerupted \\
\hline 9 & 12 & M & UCLAP & $\mathrm{Lt}$ & - & Erupted \\
\hline 10 & 8 & $\mathrm{~F}$ & BCLA & $\mathrm{Lt}$ & - & Erupted \\
\hline 11 & 8 & $\mathrm{~F}$ & BCLA & Rt & - & Erupted \\
\hline 12 & 12 & $\mathrm{~F}$ & BCLAP & $\mathrm{Lt}$ & + & Erupted \\
\hline 13 & 9 & M & UCLA & $\mathrm{Lt}$ & - & Unerupted \\
\hline 14 & 10 & M & UCLAP & $\mathrm{Lt}$ & - & Erupted \\
\hline 15 & 11 & M & UCLAP & Rt & + & Unerupted \\
\hline 16 & 9 & $\mathrm{~F}$ & BCLA & Rt & - & Unerupted \\
\hline 17 & 9 & $\mathrm{~F}$ & BCLA & $\mathrm{Lt}$ & - & Unerupted \\
\hline 18 & 12 & $\mathrm{~F}$ & BCLAP & Rt & + & Erupted \\
\hline 19 & 6 & $\mathrm{~F}$ & UCLA & Rt & - & Unerupted \\
\hline 20 & 9 & M & BCLAP & Rt & + & Erupted \\
\hline 21 & 8 & M & UCLA & $\mathrm{Lt}$ & - & Unerupted \\
\hline 22 & 9 & $\mathrm{M}$ & UCLA & Rt & - & Unerupted \\
\hline 23 & 15 & $\mathrm{~F}$ & UCLA & $\mathrm{Lt}$ & + & Erupted \\
\hline 24 & 12 & $\mathrm{~F}$ & BCLAP & Rt & - & Erupted \\
\hline 25 & 12 & $\mathrm{~F}$ & BCLAP & $\mathrm{Lt}$ & - & Erupted \\
\hline 26 & 10 & M & UCLA & $\mathrm{Lt}$ & - & Erupted \\
\hline 27 & 11 & M & UCLAP & Rt & - & Unerupted \\
\hline 28 & 10 & $\mathrm{M}$ & UCLA & $\mathrm{Lt}$ & - & Unerupted \\
\hline 29 & 9 & $\mathrm{~F}$ & UCLA & $\mathrm{Lt}$ & - & Erupted \\
\hline 30 & 10 & M & BCLAP & $\mathrm{Lt}$ & + & Erupted \\
\hline 31 & 11 & M & BCLAP & Rt & - & Erupted \\
\hline 32 & 9 & M & UCLA & Rt & - & Erupted \\
\hline 33 & 8 & $\mathrm{~F}$ & UCLAP & $\mathrm{Lt}$ & - & Unerupted \\
\hline 34 & 8 & M & UCLAP & $\mathrm{Lt}$ & - & Unerupted \\
\hline 35 & 11 & M & UCLAP & $\mathrm{Lt}$ & - & Erupted \\
\hline 36 & 9 & $\mathrm{~F}$ & UCLAP & $\mathrm{Lt}$ & - & Unerupted \\
\hline 37 & 10 & M & UCLAP & Rt & - & Erupted \\
\hline 38 & 9 & M & BCLAP & $\mathrm{Lt}$ & + & Erupted \\
\hline 39 & 10 & M & BCLAP & $\mathrm{Lt}$ & - & Erupted \\
\hline 40 & 9 & M & UCLAP & Rt & - & Erupted \\
\hline 41 & 9 & M & UCLAP & $\mathrm{Lt}$ & - & Unerupted \\
\hline 42 & 9 & M & BCLAP & $\mathrm{Lt}$ & - & Erupted \\
\hline 43 & 9 & M & UCLAP & Rt & - & Unerupted \\
\hline 44 & 9 & $\mathrm{~F}$ & UCLA & $\mathrm{Lt}$ & - & Erupted \\
\hline 45 & 10 & M & UCLAP & $\mathrm{Lt}$ & - & Unerupted \\
\hline 46 & 10 & $\mathrm{~F}$ & UCLA & $\mathrm{Lt}$ & - & Erupted \\
\hline 47 & 10 & M & UCLAP & $\mathrm{Lt}$ & - & Erupted \\
\hline 48 & 9 & $\mathrm{~F}$ & UCLA & $\mathrm{Lt}$ & - & Erupted \\
\hline 49 & 9 & M & BCLAP & Rt & - & Unerupted \\
\hline
\end{tabular}

*UCLA = unilateral cleft lip and alveolous ; UCLAP= unilateral cleft lip, alvolous and palate ; BCLA=bilateral cleft lip and alveolous ; $\mathrm{BCLAP}=$ bilateral cleft lip, alvolous and palate 


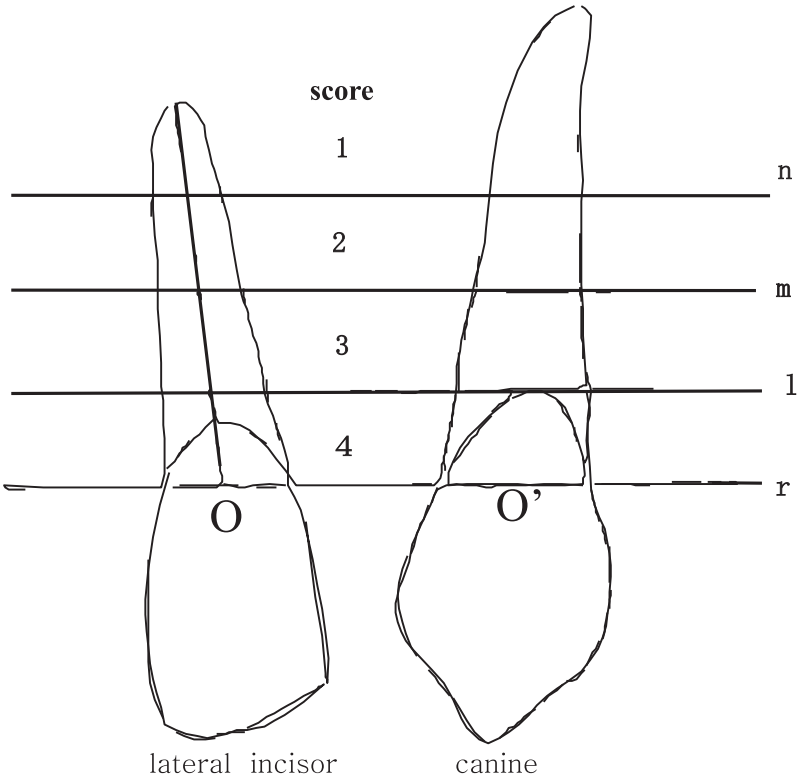

Figure 1 : The marginal bone level on teeth adjacent to the cleft As the manner of estimation of bone level, Enemark et al. classified the lowest marginal bone level in four scores.

\section{The shortest vertical length of the bone bridge}

We defined the shortest distance of the bone bridge in the craniocaudal direction on an intraoral dental radiograph as "the shortest vertical length of the bone bridge" (Figure 2).

The average root length of the maxillary lateral incisor is $13 \mathrm{~mm}$ (12-14). Kubota et al. (15) described that it was necessary to move the canine into the cleft after bone grafting if the vertical length of the bone bridge was at least half of the root length of the adjacent tooth (generally the lateral incisor). Therefore, we judged that a root length of $6.5 \mathrm{~mm}$ is enough to fix the tooth to the alveolar cleft in this study.

\section{The shortest anteroposterior bone width}

The shortest length from the labial to palatal side of the bone bridge on an axial CT image 3 months postoperatively was defined as "the shortest anteroposterior bone width" (Figure 3).

In a recent paper by Kim et al. (12), it was reported that the labiopalatal diameter of the root of the maxillary lateral incisor had a mean value of $4.51 \pm 0.51 \mathrm{~mm}$ at the center of the tooth root. Therefore, we chose $5 \mathrm{~mm}$ as the cut-off value for evaluating the shortest anteroposterior bone width at which orthodontic treatment would be advisable.

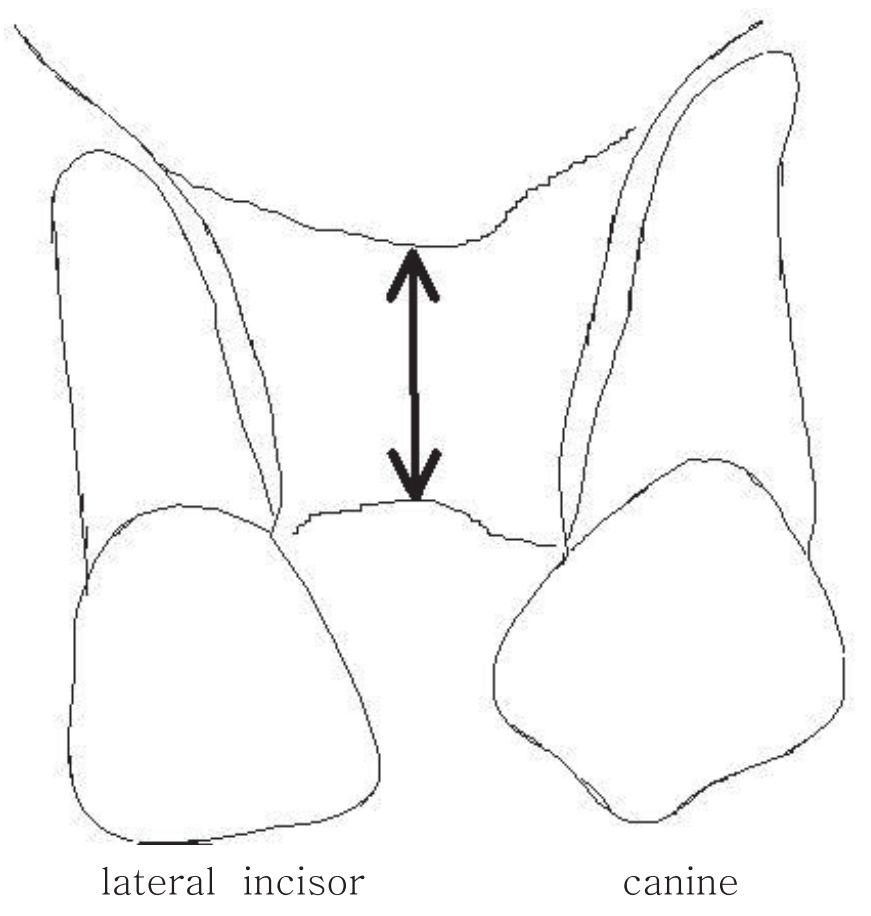

(a)

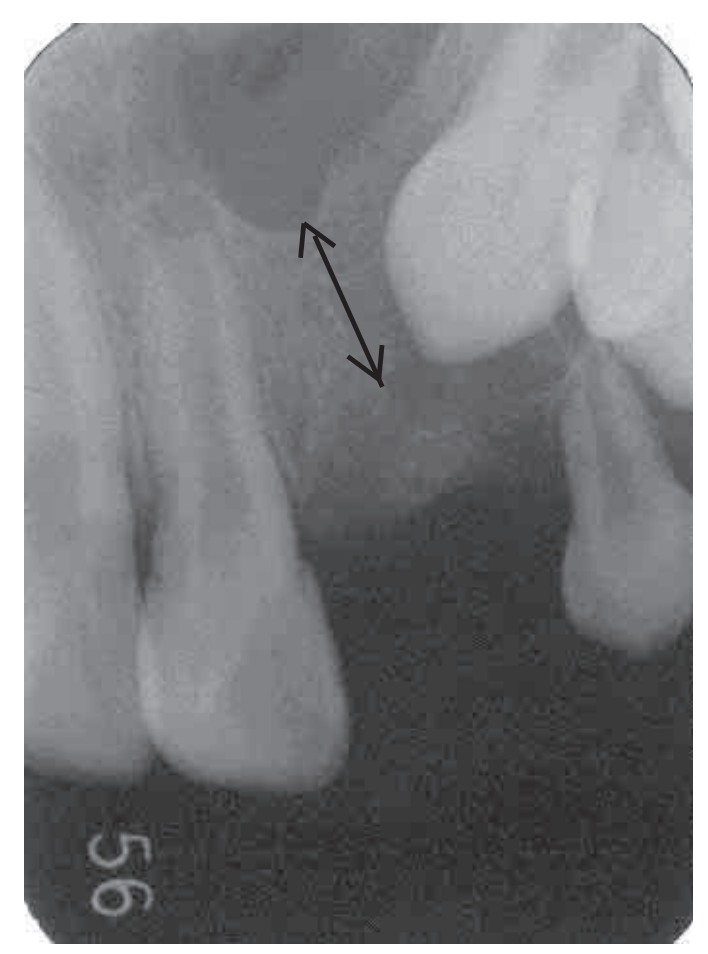

(b)

Figure 2 : The shortest vertical length of bone bridge

(a) schema (b) roentgenogram

The shortest vertical length of bone bridge was measured at three months after operation on intraoral dental roentgenogram. 


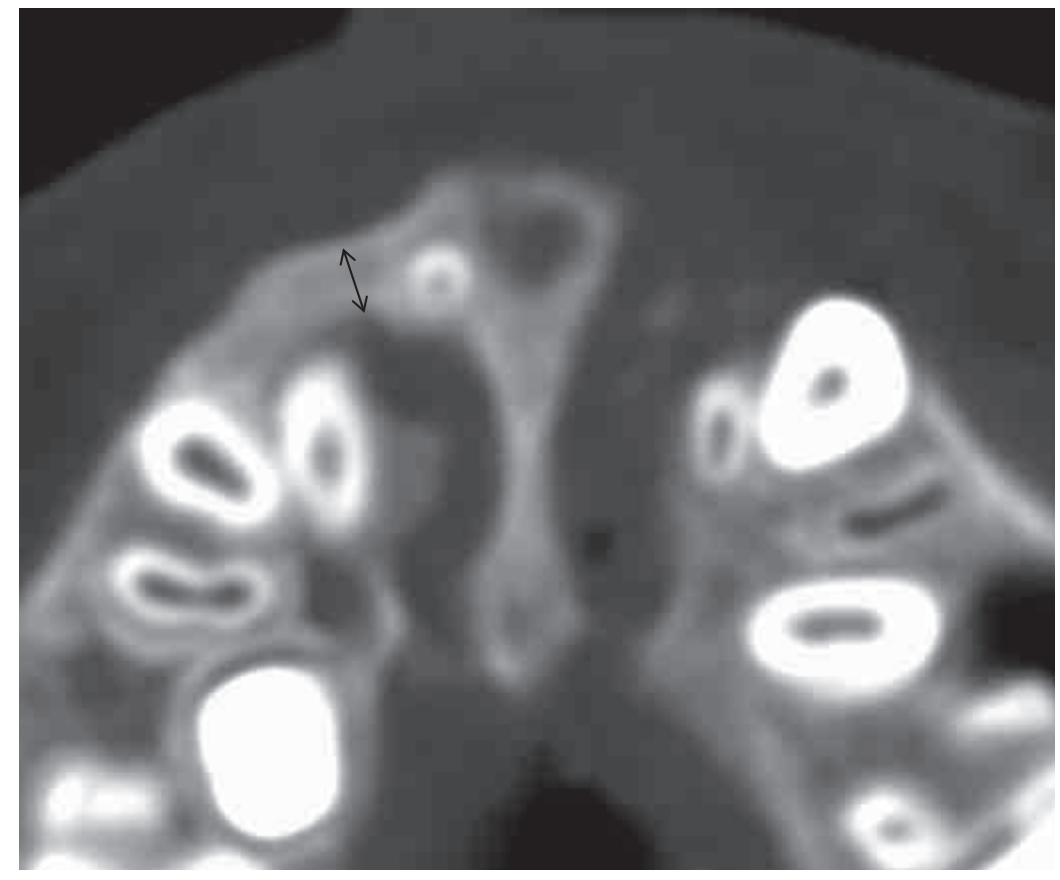

Figure 3 : The shortest anteroposterior bone width

The shortest length (arrow) from labial side to palate side of bone bridge was measured on CT.

\section{Bone mineral density of the bone bridge}

It is well known that osteoporosis causes decreased bone mineral density throughout the body and leads to various disorders because of reduced bone strength (16). Some dentists have tried using bone mineral density measurements of the jaw as the basis of decisions regarding the insertion of implants $(17,18)$. Based on these works, we believed that lower bone mineral density of the bone bridge would indicate that its strength was weak and bone formation was inadequate for an ideal occlusion. We measured bone mineral density of the bone bridge by the following methods :

During the 3-mm slice CT examination, a calibration phantom developed by Kalender et al. (5) was placed near the face of the patient. We then measured the CT number of the grafted area and calculated the bone mineral density in that area following the method of McCollough et al. (19). In brief, the bone mineral density can be calculated from its ratio to $\mathrm{CT}$ number. The calibration phantom consists of 2 kinds of material. One is equivalent to calcium hydroxyapatite with a bone mineral density of $200 \mathrm{mg} / \mathrm{mL}$ and corresponds to cortical bone, while the other is equivalent to calcium hydroxyapatite with a density of $0 \mathrm{mg} / \mathrm{mL}$ and corresponds to soft tissues (Figure 4). We measured CT numbers in these 2 materials and the grafted bone area and calculated the bone mineral density of the grafted site on the basis of the proportional relationship (Figure $5)$.

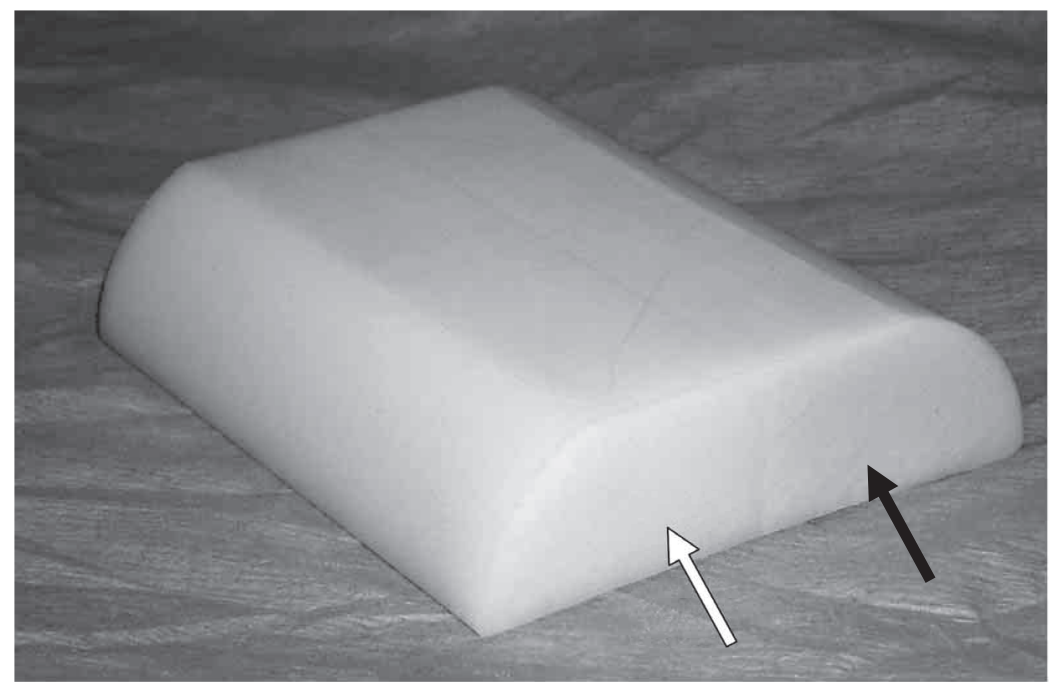

Figure 4 : Calibration phantom (designed by Will.A Kalender at Siemens Medical System (1987))

Calibration phantom consists of two kinds of matter, bone-equivalent plastic (black arrow) and water-equivalent plastic (white arrow)

width : $9 \mathrm{~cm}$, length : $10 \mathrm{~cm}$, thickness : $2.5 \mathrm{~cm}$

Bone-equivalent plastic : $200 \mathrm{mg} \mathrm{Ca} 5\left(\mathrm{PO}_{4}\right)$ $\mathrm{OH} / \mathrm{ml}$

Water-equivalent plastic : $0 \mathrm{mg}$ Ca5$\left(\mathrm{PO}_{4}\right)$ $\mathrm{OH} / \mathrm{ml}$

$\mathrm{Ca} 5\left(\mathrm{PO}_{4}\right) \mathrm{OH}=$ calcium hydroxyapatite 


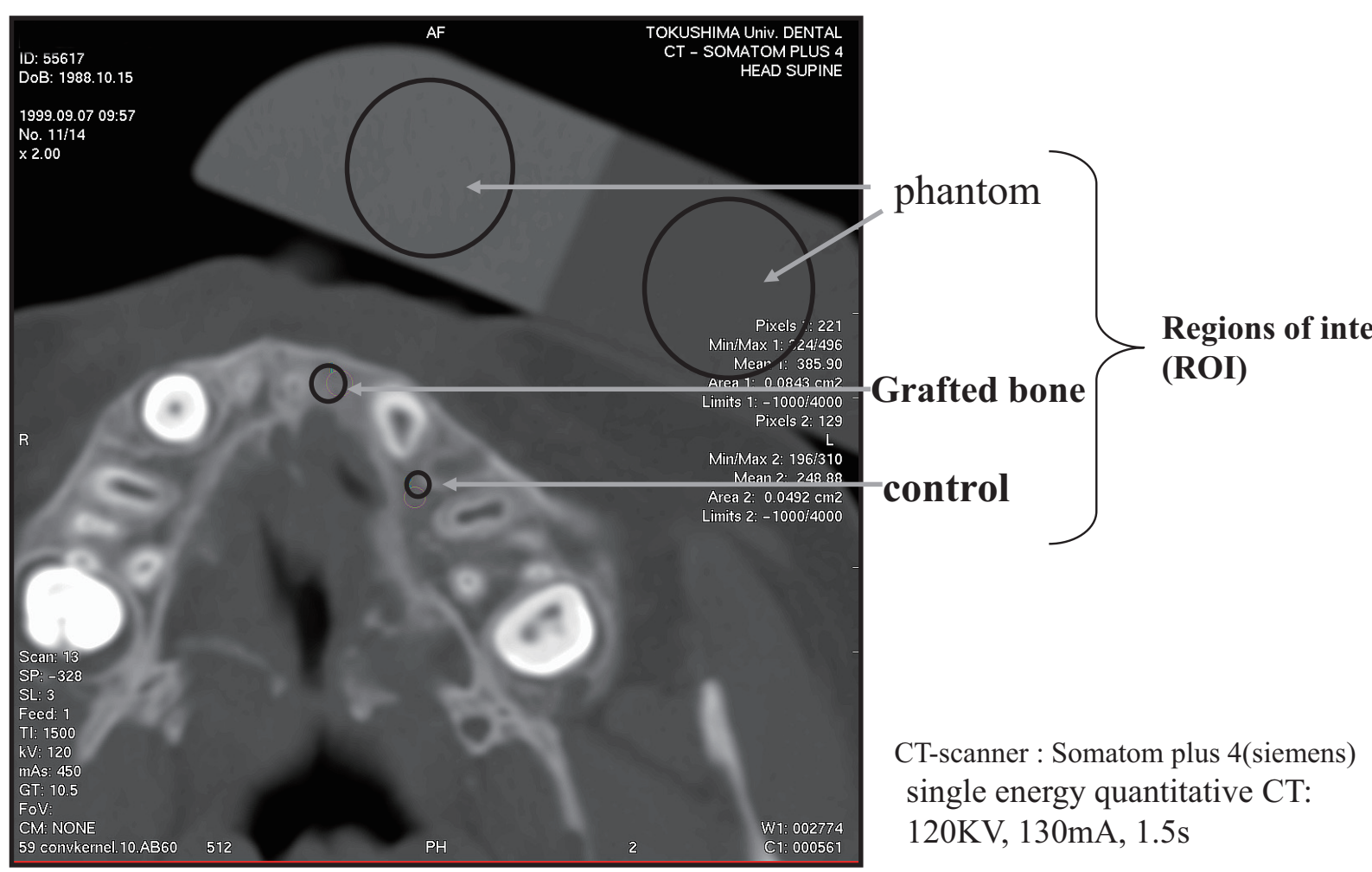

Figure 5 : Method of measuring bone mineral density with Quantitative Computed Tomography (QCT) We set ROI in bone bridge built by alveolar bone grafting and calculated bone mineral density from CT number.

Evaluation : We estimated that 1 month was sufficient for stabilization of the grafted site. A month after alveolar bone grafting, orthodontic treatment was started with the aim of causing spontaneous eruption of the adjacent teeth or orthodontic movement of the teeth adjacent to the cleft site in all cases.

When adequate alveolar bone for tooth root coverage was not observed at the grafted site, teeth were not moved parallel but obliquely, and prosthodontic treatment was provided if necessary (20).

The result of the orthodontic treatment was assessed more than 2 years after bone grafting in all patients. Bone grafting was considered "successful" if a patient's lateral incisor or canine had erupted into the grafted site or if teeth adjacent to the cleft had moved into the grafted site without the need of prosthodontic treatment. This group included patients in whom there were congenital tooth defects, and a resilient bed for implants or appropriate dentures was provided by bone grafting.

When the bone bridge in some patients was found to be inadequate for orthodontic treatment, it was necessary to perform prosthodontic rehabilitation or re-operation for bone grafting. This group was classified as "unsuccessful."
The evaluations described above were performed by a team of experienced orthodontists.

Statistical analysis : We evaluated the orthodontic treatment and radiographic examination results, marginal bone level, shortest vertical length of the bone bridge, and shortest anteroposterior bone width using the $\chi^{2}$ test. A $p$ value of $<0.05$ was considered to indicate a statistically significant difference.

\section{RESULTS}

\section{Marginal bone level}

The marginal bone level on teeth adjacent to the cleft was evaluated as score 4 in 16 of the grafted sites, score 3 in 14 , score 2 in 8 , score 1 in none, and score 0 in 11 (Figure 6).

Orthodontic treatment was successful in $24(80 \%)$ of the 30 grafted sites with scores of 3 and 4 , in comparison with $2(10.5 \%)$ of the 19 sites with scores of 0 and 2. Furthermore, there was a correlation between the 2 groups distributed in score 3 assessed using the $\chi^{2}$ test $(p<0.001)$ (Table 2).

As a result, the sensitivity between the marginal 


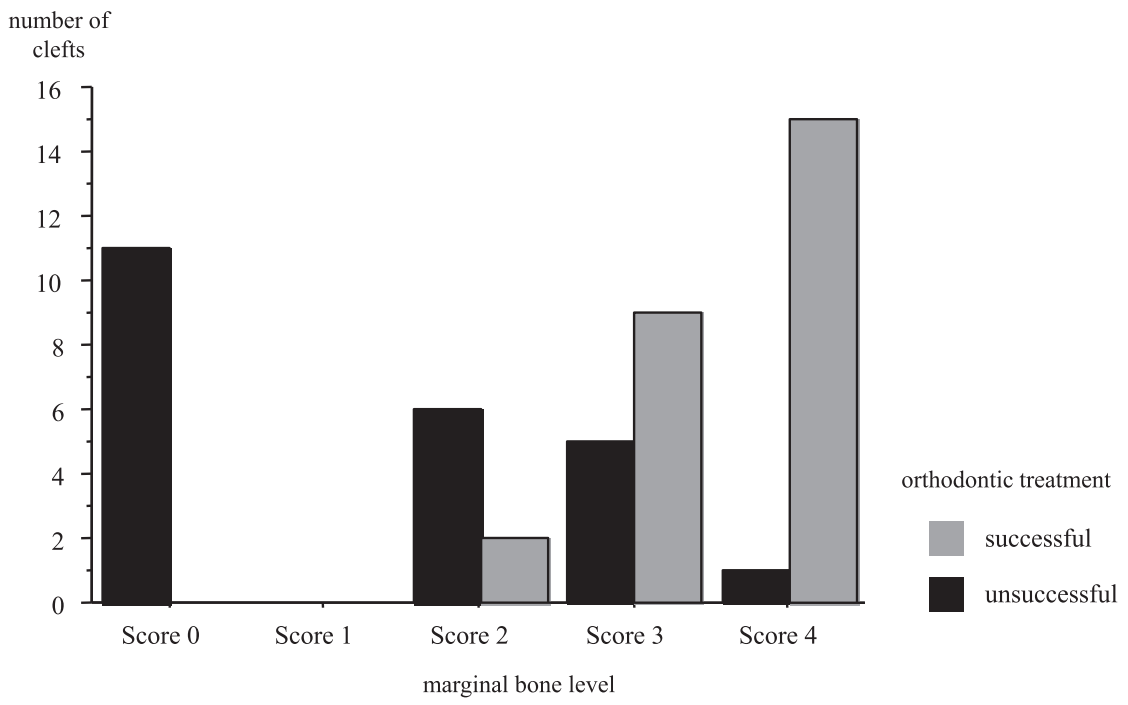

Figure 6 : The marginal bone level and judgment of orthodontic treatment

Table 2 : The correlation between two groups distributed in the score 3

\begin{tabular}{|c|c|c|}
\hline & \multicolumn{2}{|c|}{$\mathrm{P}$-value $<0.001$} \\
\hline $\begin{array}{l}\text { MBL } \\
\text { orthodontic } \\
\text { treatment }\end{array}$ & $\geqq 3$ & $\begin{array}{c}1 \\
<3\end{array}$ \\
\hline successful & 24 & 2 \\
\hline unsuccessful & 6 & 17 \\
\hline
\end{tabular}

$\mathrm{MBL}=$ marginal bone level

sensitivity $=24 / 26(92.3 \%):$ specificity $=17 / 23(73.9 \%)$ bone level and orthodontic treatment showed 92.3\% and the specificity between them showed $73.9 \%$.

\section{The shortest vertical length of the bone bridge}

Data of "the shortest vertical length" and "orthodontic treatment" are represented by a box and whisker plot (Figure 7). This result suggests that orthodontic treatment can be successful if the shortest vertical length of the bone bridge is $>6 \mathrm{~mm}$ after alveolar bone grafting.

In this study, the cut-off value was $6.5 \mathrm{~mm}$ for evaluating the shortest vertical length of the bone bridge. All grafted sites were divided into the following 2 groups based on this cut-off value. One

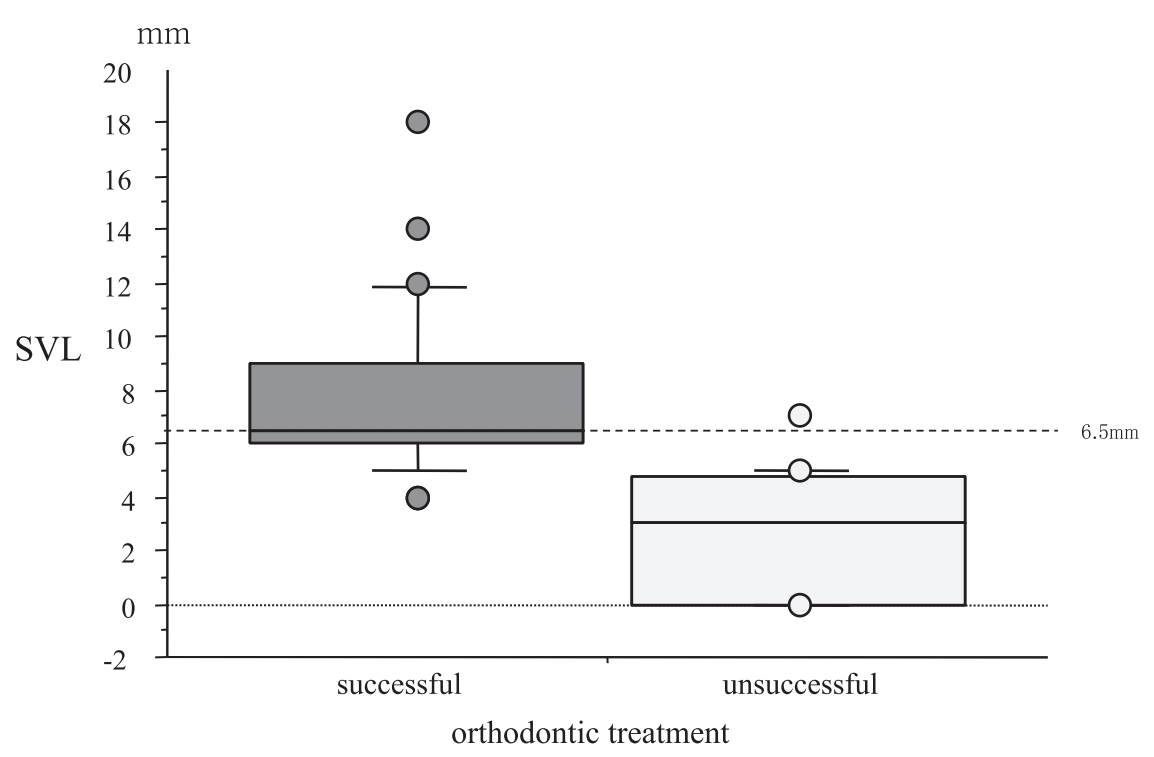

$\mathrm{SVL}=$ The shortest vertical length of bone bridge

Figure 7 : The shortest vertical length of bone bridge and orthodontic treatment 
group, with the shortest vertical length of the grafted alveolar bone of $<6.5 \mathrm{~mm}$, exhibited a $37.1 \%$ success rate of the orthodontic treatment after bone grafting (13/35 sites). The other group, with the shortest vertical length of $\geqq 6.5 \mathrm{~mm}$, exhibited a $92.9 \%$ success rate of the orthodontic treatment (13/ 14 sites). There was a significant difference between the 2 groups ( $p=0.004)$ (Table. 3 ).

As a result, the sensitivity between the shortest vertical length of bone bridge and orthodontic treatment showed $50 \%$ and the specificity between them showed $95.7 \%$.

\section{The shortest anteroposterior bone width}

At the position of the midpoint of tooth root of the central or lateral incisor, the median value of the shortest anteroposterior bone width was $5.4 \mathrm{~mm}$. The cut-off value was $5 \mathrm{~mm}$ for evaluating the shortest anteroposterior bone width (Fig. 8).

Table 3 : The correlation between two groups divided by $6.5 \mathrm{~mm}$ about the shortest vertical length of bone bridge

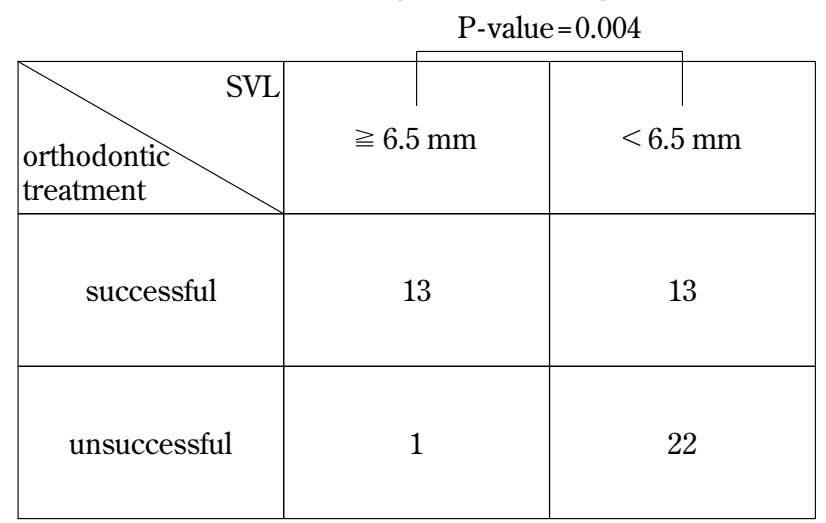

$\mathrm{SVL}=$ shortest vertical length sensitivity $=13 / 26(50 \%)$ : specificity $=22 / 23(95.7 \%)$

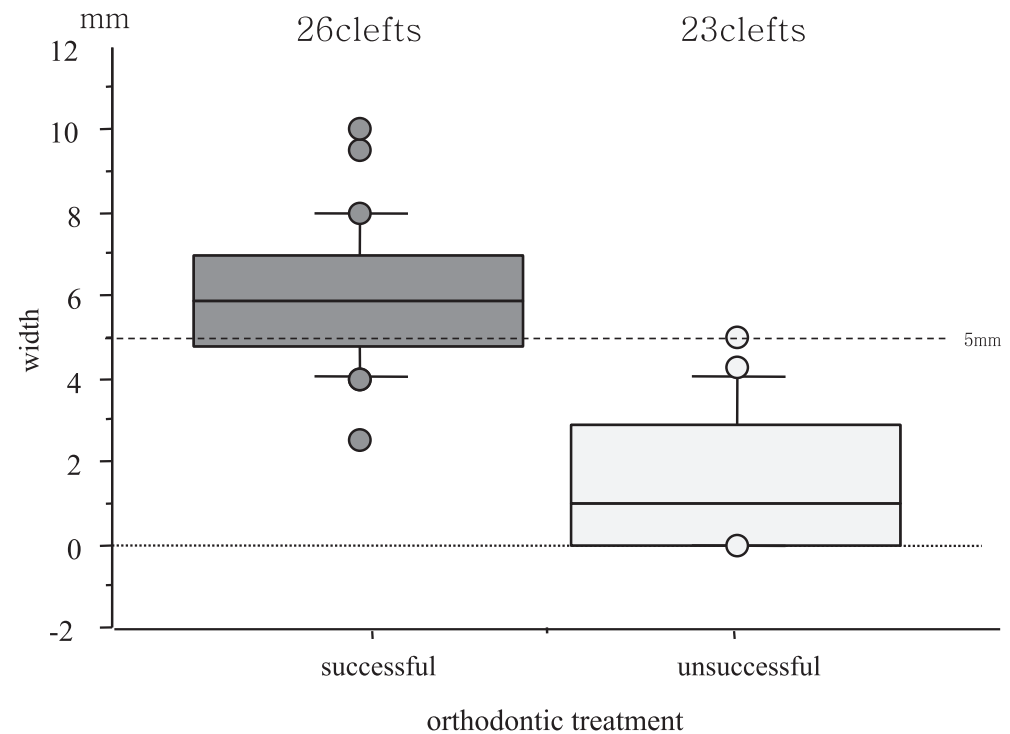

Figure 8 : The shortest anteroposterior bone width vs. judgement of orthodontic treatment
The group in which the shortest anteroposterior bone width was $\geqq 5 \mathrm{~mm}$, orthodontic treatment was successful in 18 of the 19 sites (94.7\%). The other group with anteroposterior bone width $<5 \mathrm{~mm}$, treatment was successful in 8 of the 30 sites (26.7\%). There was a significant difference between the 2 groups $(p<0.001)$ (Table. 4$)$.

As a result, the sensitivity between the shortest anteroposterior bone width and orthodontic treatment showed $69.2 \%$ and the specificity between them showed $95.7 \%$.

\section{Bone mineral density of the bone bridge}

We reviewed the relationship between the bone mineral density of the bone bridge and success rate of orthodontic treatment in 38 of the 49 sites. The remaining 11 sites were excluded because no bone bridge was formed (Figure 9).

Table 4 : The correlation between two groups divided $5 \mathrm{~mm}$ about the shortest anteroposterior bone width

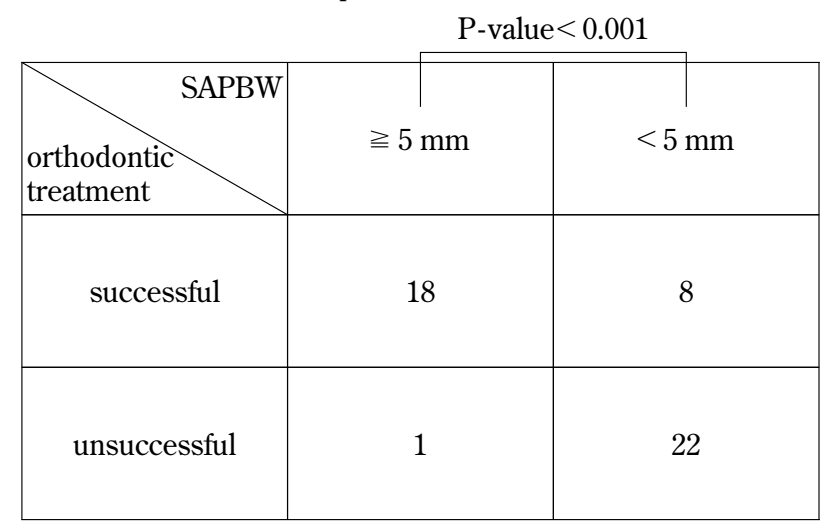

SAPBW $=$ shortest anteroposterior bone width sensitivity $=18 / 26(69.2 \%):$ specificity $=17 / 23(95.7 \%)$ 


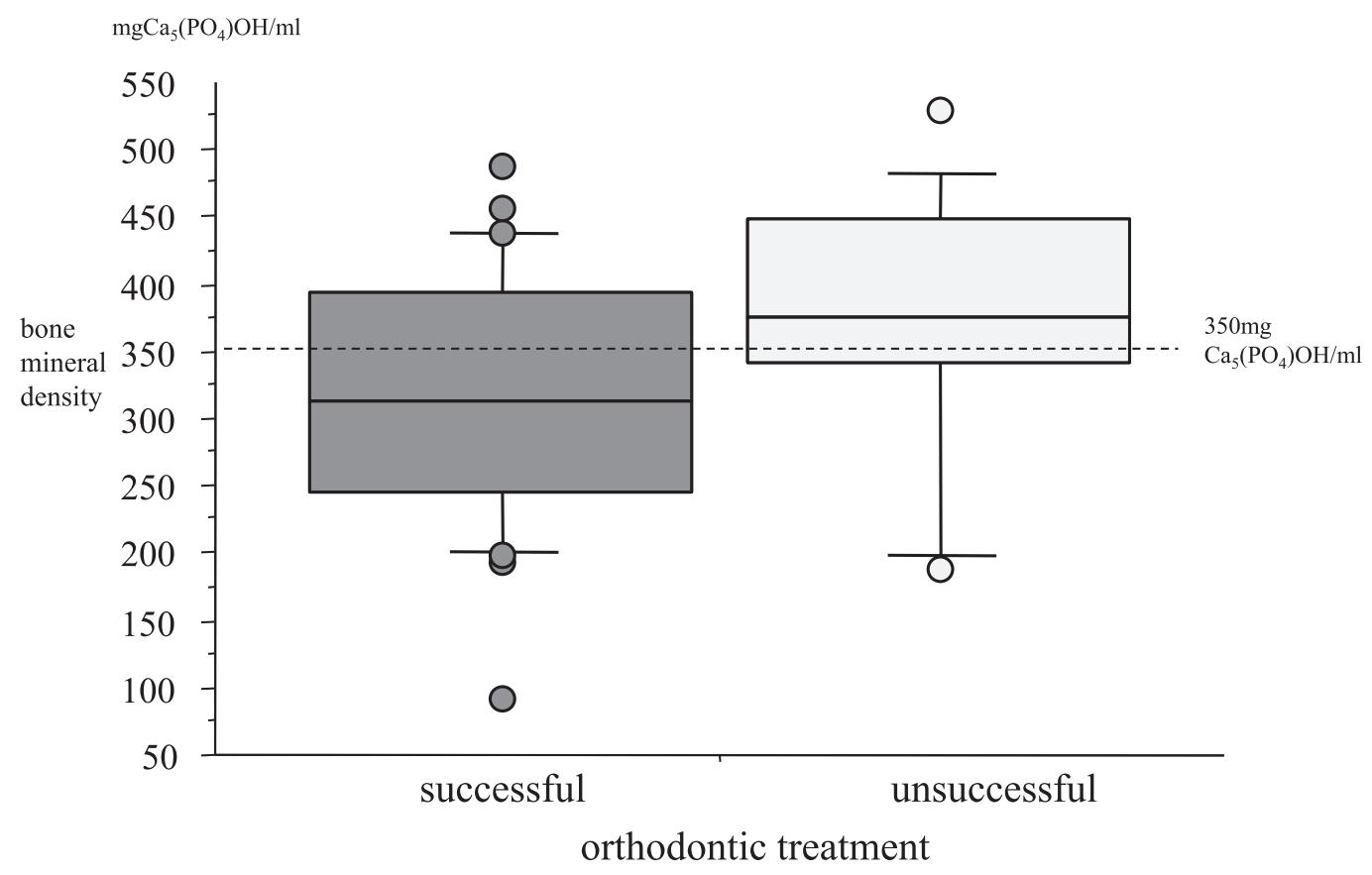

Figure 9 : The correlation between bone mineral density and orthodontic treatment

The average bone mineral density of the alveolar cancellous bone at the nongrafted side was 315.49 $\mathrm{mg} \mathrm{Ca}\left(\mathrm{PO}_{4}\right) \mathrm{OH} / \mathrm{mL}$. On the other hand, the average bone mineral density of the bone bridge was $334.60 \mathrm{mg} \mathrm{Ca}\left(\mathrm{PO}_{4}\right) \mathrm{OH} / \mathrm{mL}$. Furthermore, it was shown that the borderline between a "successful" and an "unsuccessful" graft was $350 \mathrm{mg} \mathrm{Ca}\left(\mathrm{PO}_{4}\right)$ $\mathrm{OH} / \mathrm{mL}$ (Figure 9). Therefore, we chose $350 \mathrm{mg}$ $\mathrm{Ca}_{5}\left(\mathrm{PO}_{4}\right) \mathrm{OH} / \mathrm{mL}$ as the cut-off value for adequate bone mineral density in this study.

Thirty-eight clefts were divided into 2 groups with bone mineral density above or below $350 \mathrm{mg}$ $\mathrm{Ca}_{5}\left(\mathrm{PO}_{4}\right) \mathrm{OH} / \mathrm{mL}$. There were 17 clefts in patients with bone mineral densities $\geqq 350 \mathrm{mg} \mathrm{Ca} 5\left(\mathrm{PO}_{4}\right)$ $\mathrm{OH} / \mathrm{mL}$. Among these 17, 8 clefts (47.1\%) exhibited a "successful" outcome of orthodontic treatment, while 9 (52.9\%) were "unsuccessful". On the other hand, there were 21 clefts in patients with bone mineral densities $<350 \mathrm{mg} \mathrm{Ca}\left(\mathrm{PO}_{4}\right) \mathrm{OH} / \mathrm{mL}$. Among these, 18 clefts (85.7\%) exhibited a "successful" outcome, while only 3 cleft treatments were "unsuccessful." Therefore, when bone mineral density of the bone bridge was $\geqq 350 \mathrm{mg} \mathrm{Ca} 5\left(\mathrm{PO}_{4}\right) \mathrm{OH} / \mathrm{mL}$, there was no correlation between bone mineral density and the outcome of orthodontic treatment $(p=$
0.959). However, when bone mineral density was $<350 \mathrm{mg}$, orthodontic treatment was likely to be successful, and the difference between these results was statistically significant $(p<0.001)$ (Table 5).

Table 5 : The correlation between two groups divided $350 \mathrm{mg}$ $\mathrm{Ca} 5\left(\mathrm{PO}_{4}\right) \mathrm{OH} / \mathrm{ml}$ about bone mineral density

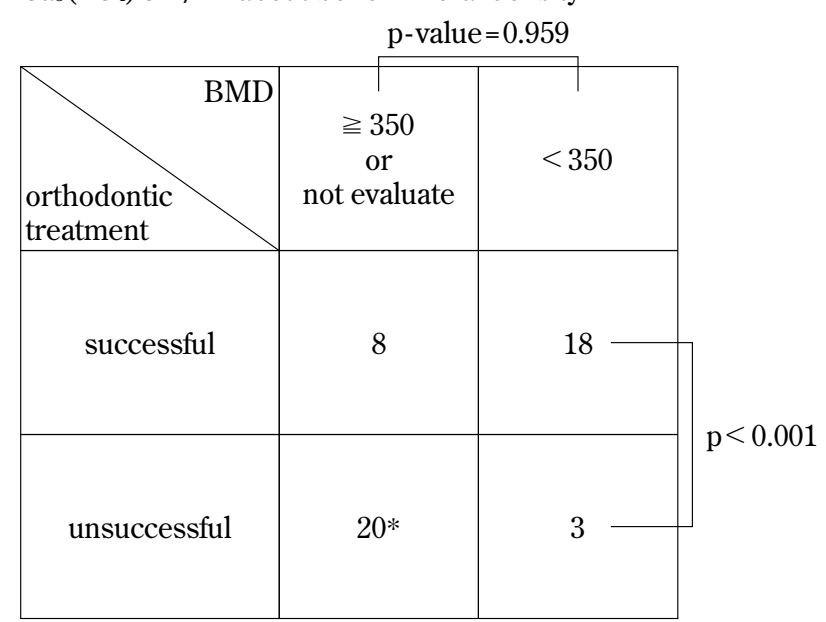

$\mathrm{BMD}=$ bone mineral density

*including to 11 clefts that formed no bone bridge sensitivity $=18 / 26(69.2 \%)$ : specificity $=20 / 23(87.0 \%)$ 
As a result, the sensitivity between bone mineral density and orthodontic treatment showed $69.2 \%$ and the specificity between them showed $87.0 \%$.

\section{DISCUSSION}

Secondary alveolar bone grafting for cleft lip and palate was first reported in 1972 by Boyne (21) and has become a popular and standard procedure for orthodontic treatment. The timing and procedures used in this grafting have almost become standardized in recent years. Optimal timing is at an age of mixed dentition is usually about 10 years old in the Japanese population (15, 22-24). An autogenous cancellous bone graft from the iliac crest is the most popular procedure and provides alveolar cleft patients with stable results.

The purposes of alveolar bone grafting for orthodontic treatment are as follows : 1) eruption of permanent teeth, 2) movement of neighboring teeth, 3) closing of oronasal fistula, 4) formation of construction around piriform aperture, and 5) stabilization of maxilla.

In the past, methods available to evaluate the results of bone grafts were mainly 2-dimensional radiographs, such as dental, occlusal, and panoramic radiographs $(11,20,25-28)$. However, these methods sometimes contain inherent distortion factors, and it has been reported that estimations based on these radiographs are not consistent with the actual outcome of the orthodontic treatment $(10,29)$. Therefore, the usefulness of the 3 -dimensional imaging using CT was assessed in determining whether a bone bridge built by alveolar bone grafting had sufficient volume for the eruption of permanent teeth and neighboring tooth movement (30).

We firmly believe that the clinical goal of alveolar bone grafting is a successful orthodontic treatment, such as the eruption of permanent teeth and movement of the neighboring tooth.

We evaluated the clinical outcome of orthodontic treatment; in addition to evaluating the bone bridge by measuring the marginal bone level, shortest vertical length, shortest anteroposterior width, and bone mineral density using dental radiographs and QCT. We assessed the bone bridge 3 months after operation, because several authors have reported that there was little difference between the bone bridge at 3 months postoperatively and the bone bridge after 6 months or 1 year $(12,19)$. In addition, it is necessary to evaluate the bone bridge and restart a patient's orthodontic treatment or perform re-operation as soon as possible.

Most of the patients in need of alveolar bone grafting are school children and find it hard to accept hospitalization for approximately 2-3 weeks. If these patients cannot receive appropriate orthodontic treatment and are considered for re-grafting for an alveolar cleft 2 or 3 years after initial surgery, they may not be able to be hospitalized and undergo surgery immediately because of school commitments. We evaluated the bone bridge as early as possible, to confirm the assumption that orthodontic treatment can be resumed and that there was no need of bone graft again.

In this study, we found several distinct features on images of the grafted site, which could indicate whether orthodontic treatment was likely to be successful. These features are : marginal bone level of $\geqq 3$, shortest vertical length of $\geqq 6.5 \mathrm{~mm}$, shortest anteroposterior bone width of $\geqq 5 \mathrm{~mm}$ and bone mineral density $<350 \mathrm{mg} \mathrm{Ca}\left(\mathrm{PO}_{4}\right) \mathrm{OH} / \mathrm{mL}$.

The results of the clinical evaluation of the bone bridge parameters are shown in Table 6 . With regard to the marginal bone level, 30 of the 49 clefts scored $\geqq 3$ when 3 was designated as the cut-off value. The positive rate for successful dental treatment was $80 \%$. In addition, only 14 alveolar clefts had "shortest vertical length of bone bridge $\geqq 6.5$ mm" with a high success rate of $92.9 \%$. Similarly, 19 clefts had "shortest anteroposterior bone width $\geqq 5$ mm" with a success rate of $94.7 \%$. On the other hand, 21 clefts had "bone mineral density $<350 \mathrm{mg}$ $\mathrm{Ca}_{5}\left(\mathrm{PO}_{4}\right) \mathrm{OH} / \mathrm{mL}$ " with a success rate of $85.7 \%$.

Among the clefts assessed as marginal bone level of $\geqq 3$, treatments of 6 clefts were considered "unsuccessful." The values of the shortest anteroposterior bone width of all these 6 clefts were $<5 \mathrm{~mm}$. One cleft treatment was considered "unsuccessful" among the clefts in which the "shortest vertical length of the bone bridge $\geqq 6.5 \mathrm{~mm}$." These 7 clefts were evaluated as good based on dental radiographs, but the results of orthodontic treatment were considered "unsuccessful", and the same 7 clefts were evaluated as "not good" by CT scans.

In addition, we reviewed the results of orthodontic treatment with regard to "marginal bone level" and "shortest vertical length of bone bridge" that were possible on dental radiographs (Table 7). All clefts that satisfied both conditions, namely marginal bone level $\geqq 3$ and the shortest vertical length of bone bridge $\geqq 6.5 \mathrm{~mm}$, were able to achieve an ideal occlusion. 
Table 6 : evaluation of bone bridge

\begin{tabular}{|c|c|c|c|c|c|}
\hline No. & $\begin{array}{c}\text { The marginal } \\
\text { bone level }\end{array}$ & $\begin{array}{l}\text { The shortest vertical length } \\
\text { of bone bridge }\end{array}$ & $\begin{array}{l}\text { The shortest anteroposterior } \\
\text { bone width }\end{array}$ & $\begin{array}{l}\text { Bone mineral density of } \\
\text { bone bridge }\end{array}$ & \multirow{2}{*}{$\begin{array}{l}\text { orthodontic treatent } \\
\text { clinical evaluation }\end{array}$} \\
\hline & \multicolumn{2}{|c|}{ evaluated by dental radiograph } & \multicolumn{2}{|c|}{ evaluated by CT scan } & \\
\hline 1 & 3 & 6.0 & 5.0 & 198.55 & success \\
\hline 2 & 4 & 7.0 & 8.0 & 333.33 & success \\
\hline 3 & 2 & 7.0 & 2.0 & 403.44 & not success \\
\hline 4 & 3 & 14.0 & 6.5 & 90.73 & success \\
\hline 5 & 4 & 6.0 & 5.0 & 329.41 & success \\
\hline 6 & 2 & 4.0 & 2.5 & 439.12 & success \\
\hline 7 & 3 & 8.0 & 8.0 & 239.32 & success \\
\hline 8 & 3 & 7.0 & 6.0 & 282.83 & success \\
\hline 9 & 2 & 5.0 & 5.0 & 459.45 & not success \\
\hline 10 & 3 & 7.0 & 5.0 & 436.18 & success \\
\hline 11 & 3 & 5.0 & 4.0 & 528.67 & not success \\
\hline 12 & 0 & 0.0 & 0.0 & not evaluate & not success \\
\hline 13 & 2 & 4.0 & 1.0 & 187.40 & not success \\
\hline 14 & 4 & 6.0 & 6.0 & 337.00 & success \\
\hline 15 & 0 & 0.0 & 0.0 & not evaluate & not success \\
\hline 16 & 3 & 8.0 & 7.0 & 221.76 & success \\
\hline 17 & 4 & 6.0 & 5.0 & 288.19 & success \\
\hline 18 & 3 & 4.0 & 4.0 & 394.46 & success \\
\hline 19 & 0 & 0.0 & 0.0 & not evaluate & not success \\
\hline 20 & 4 & 5.0 & 4.3 & 487.63 & success \\
\hline 21 & 4 & 6.0 & 4.0 & 374.27 & success \\
\hline 22 & 4 & 7.0 & 8.0 & 330.02 & success \\
\hline 23 & 4 & 10.0 & 10.0 & 261.13 & success \\
\hline 24 & 3 & 3.0 & 4.3 & 330.02 & not success \\
\hline 25 & 3 & 3.0 & 3.0 & 435.80 & not success \\
\hline 26 & 0 & 0.0 & 0.0 & not evaluate & not success \\
\hline 27 & 0 & 0.0 & 0.0 & not evaluate & not success \\
\hline 28 & 3 & 5.0 & 3.0 & 358.00 & not success \\
\hline 29 & 3 & 5.0 & 7.0 & 305.44 & success \\
\hline 30 & 0 & 0.0 & 0.0 & not evaluate & not success \\
\hline 31 & 0 & 0.0 & 0.0 & not evaluate & not success \\
\hline 32 & 2 & 4.0 & 2.6 & 351.30 & not success \\
\hline 33 & 2 & 4.0 & 1.9 & 204.91 & not success \\
\hline 34 & 0 & 0.0 & 0.0 & not evaluate & not success \\
\hline 35 & 4 & 11.0 & 6.4 & 192.09 & success \\
\hline 36 & 2 & 4.0 & 4.0 & 369.95 & not success \\
\hline 37 & 0 & 0.0 & 0.0 & not evaluate & not success \\
\hline 38 & 3 & 5.0 & 2.0 & 461.66 & not success \\
\hline 39 & 4 & 11.0 & 9.5 & 312.29 & success \\
\hline 40 & 0 & 0.0 & 0.0 & not evaluate & not success \\
\hline 41 & 4 & 6.0 & 4.3 & 429.14 & success \\
\hline 42 & 4 & 12.0 & 7.0 & 418.20 & success \\
\hline 43 & 0 & 0.0 & 0.0 & not evaluate & not success \\
\hline 44 & 3 & 9.0 & 4.9 & 312.74 & success \\
\hline 45 & 4 & 5.0 & 4.8 & 225.91 & success \\
\hline 46 & 4 & 6.0 & 4.3 & 299.72 & success \\
\hline 47 & 2 & 5.0 & 5.7 & 245.67 & success \\
\hline 48 & 4 & 5.0 & 2.2 & 382.58 & not success \\
\hline 49 & 4 & 18.0 & 6.4 & 456.58 & success \\
\hline
\end{tabular}


Table 7 : Parameters by dental radiograph and orthodontic treatment results

\begin{tabular}{|c|c|c|}
\hline $\begin{array}{r}\text { evaluation by dental } \\
\text { radiograph } \\
\text { orthodontic } \\
\text { treatment }\end{array}$ & $\begin{array}{r}\text { matched } \\
(\mathrm{MBL} \geqq 3, \mathrm{SVL} \geqq 6.5)\end{array}$ & not matched \\
\hline successful & 13 & 13 \\
\hline unsuccessful & 0 & 23 \\
\hline
\end{tabular}

$\mathrm{MBL}=$ marginal bone level

$\mathrm{SVL}=$ the shortest vertical length of bone bridge

sensitivity $=13 / 26(50.0 \%):$ specificity $=23 / 23(100 \%)$

Therefore, specificity is $100 \%$, but sensitivity is confined to $50 \%$.

We also evaluated the result of orthodontic treatment based on "shortest anteroposterior bone width" and "bone mineral density." Both conditions could be measured by CT scan (Table 8). All clefts that satisfied both these conditions achieved an ideal occlusion with a specificity of $100 \%$ but sensitivity of only $57.7 \%$.

Table 8 : Parameters by CT scans and orthodontic treatment results

\begin{tabular}{|c|c|c|}
\hline $\begin{array}{l}\text { evaluation by } \\
\text { CT scans } \\
\text { orthodontic } \\
\text { treatment }\end{array}$ & $\begin{array}{c}\text { matched } \\
(\mathrm{SAPBW} \geqq 6.5, \\
\mathrm{BMD}<350)\end{array}$ & not matched \\
\hline successful & 15 & 11 \\
\hline unsuccessful & 0 & 23 \\
\hline
\end{tabular}

SAPBW $=$ shortest anteroposterior bone width

$\mathrm{BMD}=$ bone mineral density

sensitivity $=15 / 26(57.7 \%):$ specificity $=23 / 23(100 \%)$

In this study, the parameters, which were chosen to be used in dental radiographs and CT scans, were able to select clefts that could achieve an ideal occlusion by 3 months postoperatively with a high specificity rate (100\%). However, we were not only able to achieve sensitivity of $50 \%$ and $57.7 \%$ from dental radiographs and CT scans, respectively. The parameters that we evaluated in this study seemed to be inadequate for predicting the results of orthodontic treatment. Therefore, we intend to create a new parameter in order to predict the prognosis of orthodontic treatment. However, too many types of examinations and measurements will bother and burden patients. In addition, a new CT scan system such as cone-beam CT or dental CT, which can acquire enough data with a smaller exposure dose, is becoming popular (31-33). We believe that more appropriate parameters, mainly on CT scans, will become necessary in the future.

\section{CONCLUSION}

We evaluated and analyzed the quantity and quality of the bone bridge 3 months postoperatively in 41 patients who received bone graft surgery at the Tokushima University Hospital from 1998 to 2001. The methods of evaluation were dental radiographs and CT scans.

Based on our results, we could predict the prognosis of patients' orthodontic treatment after bone grafting to some extent. We believe that our results may become a useful guide to medical care in alveolar bone grafting.

\section{STATEMENT OF INTERESTS}

None of the authors has a financial interest in any of the products, devices, or drugs mentioned in this manuscript. There is no source of funding. All procedures were conducted in accordance with the Declaration of Helsinki.

\section{REFERENCES}

1. Jia YK, Fu MK, Ma L : Long-term outcome of secondary alveolar bone grafting in patients with various types of cleft. $\mathrm{Br} \mathrm{J}$ Oral Maxillofac Surg 44 : 308-312, 2006

2. Newlands LC : Secondary alveolar bone grafting in cleft lip and palate patients. Br J Oral Maxillofac Surg 38 : 488-491, 2000

3. Van der Meij AJW, Baart JA, Prahl-Andersen B, Valk J, Kostense PJ, Tuinzing DB : Bone volume after secondary bone grafting in unilateral and bilateral clefts determined by computed tomography scans. Oral Surg Oral Med Oral Pathol Oral Radiol Endod 92 : 136-41, 2001 
4. Honma K, Kobayashi T, Nakajima T, and Hayasi $\mathrm{T}$ : Computed tomographic evaluation of bone formation after secondary bone grafting of alveolar clefts. J Oral Maxillofac Surg 57 : 1209-13, 1999

5. Kalender WA, Suess C : A new calibration phantom for quantitative computed tomography. Med Phys 14 : 863-866, 1987

6. Cann CE, Genant HK, Ettinger B, and Gordon GS : Spinal mineral loss in oophorectomized women. Determination by quantitative computed tomography. JAMA 244 : 2056-2059, 1980

7. Richardson ML, Genant HK, Cann CE, Ettinger $\mathrm{B}$ : Assessment of metabolic bone diseases by quantitative computed tomography. Clin Orthop 195 : 224-238, 1985.

8. LaRossa D, Buchman S, Rothkopf DM, Mayro $\mathrm{R}$, Randall $\mathrm{P}:$ A comparison of iliac and cranial bone in secondary grafting of alveolar clefts. Plast Reconstr Surg 96(4) : 789-797, 1995

9. Hall HD, Posnick CJ : Early results of secondary bone grafts in 106 alveolar clefts. J Oral Maxillofac Surg 41(5) : 289-294, 1983

10. Lee C, Crepeau RJ, Williams HB, Schwartz S : Alveolar cleft bone grafts : results and imprecisions of the dental radiograph. Plast Reconstr Surg 96(7) : 1534-1538, 1995

11. Enemark H, Sindet-Pedersen S, Bundgaard M : Long-term results after secondary bone grafting of alveolar clefts. J Oral Maxillofac Surg 45 : 913-918, 1987

12. Kim JH, Lee JG, Han DH, Kim HJ : Morphometric analysis of the anterior region of the maxillary bone for immediate implant placement using micro-CT. Clin Anat 24 : 462-468, 2011

13. Ozaki T, Satake T, Kanazawa E : Morphological significance of root length variability in comparison with other crown dimensions I. Basic Statistics and Sex Difference. J Nihon Univ Sch Dent 29(4) : 233-240, 1987

14. Bjorndal AM, Henderson WG, Skidmore AE, Kellner FH : Anatomic measurements of human teeth extracted from males between the ages of 17 and 21 years. Oral Surg 38(5) : 791803, 1974

15. Kubota $Y$, Taniguchi T, Yamashiro T, Suzuki A, Ninomiya F, Takenoshita Y, Shirasuna K : Postoperative evaluation of secondary particular cancellous bone and marrow grafting to alveolar clefts (in Japanese with English abstract). J. Jpn. Cleft Palate Assoc 28 : 1-8, 2003

16. Lenchik L, Shi R, Register TC, Beck SR,
Langefeld CD, Carr JJ : Measurement of trabecular bone mineral density in the thoracic spine using cardiac gated quantitative computed tomography. J Comput Assist Tomogr 28(1) : 134-139, 2004

17. Maki k, Okano T, Morohashi T, Yamada S, Shibaski Y : The application of 3-dimensional quantitative computed tomography to the maxillofacial skeleton. Dentomaxillofac Radiol 26 (1) : 39-44, 1997

18. Lindh C, Obrant K, Peterson A : Maxillary bone mineral density and its relationship to the bone mineral density of the lumbar spine and hip. Oral Surg Oral Med Oral Pathol Oral Radiol Endod 98(1) : 102-109, 200

19. McCollough $\mathrm{CH}$, Kaufmann RB, Cameron BM, Katz DJ, Sheedy PF 2nd, Peyser PA : Electronbeam CT: use of a calibration phantom to reduce variability in calcium quantitation. Radiology 196 : 159-165, 1995

20. Iino $M$, Kochi $S$, Matsui $K$, Tamaki $Y$, Takahashi T, Yamaguchi T, Echigo S, Tejima $\mathrm{T}$ : Secondary bone grafting of alveolar clefts using autogenous particulate cancellous bone and marrow harvested from iliac bone. Evaluation of the bone bridging by means of X-ray computed tomography. J Jpn Cleft Palate Assoc 19 : 22-31, 1994 (in Japanese with English abstract)

21. Boyne PJ : Seondary bone grafting of residual alveolar and palatal clefts. J Oral Surg 30 : 8792, 1972

22. Freihofer HP, Borstlap WA, Kuijpers-Jagtman AM, Voorsmit RA, van Damme PA, Heidbüchel KL, Borstlap-Engels VM : Timing and transplant materials for closure of alveolar clefts. A clinical comparison of 296 cases. J Craniomaxillofac Surg 21(4) : 143-148, 1993

23. Kochi S, Igari T, Iino M, Matsui $\mathrm{K}$, Takahashi T, Fukuda M, Chiba M : Autogenous Particulate Marrow and Cancellous Bone Grafting in Alveolar Clefts(in Japanese with English abstract). J Jpn Cleft Palate Assoc 20 : 59-74, 1995

24. Naitoh H, Yamawaki Y, Morimoto N, Nishimura $\mathrm{Y}: 3 \mathrm{D}-\mathrm{CT}$ evaluation of secondary alveolar bone grafts in alveolar clefts (in Japanese with English abstract). J Jpn PRS 22 : 491-499, 2002

25. Kindelan JD, Nashed RR, Bromige MR : Radiographic assessment of secondary autogenous alveolar bone grafting in cleft lip and palate patients. Cleft Palate Craniofac J 34 : 195-198, 1997 
26. Honma K, Kobayashi T, Nakajima T, Hayashi $\mathrm{T}$ : Computed tomographic evaluation of bone formation after secondary bone grafting of alveolar clefts. J Oral Maxillofac Surg 57 : 12091213, 1999

27. Tai EC, Sutherland SI, McFadden L: Prospective Analysis of Secondary Alveolar Bone Grafting Using Computed Tomography. J Oral Maxillofac Surg 58 : 1241-1249, 2000

28. Witherow H, Cox S, Jones E, Carr R, Waterhouse $\mathrm{N}$ : A new scale to assess radiographic success of secondary alveolar bone grafts. Cleft Palate Craniofac J 39(3) : 255-260, 2002

29. Iino M, Ishi $H$, Matsushima R, Fukuda $M$, Hamada Y, Kondoh T, Seto K : Comparison of intraoral radiography and computed tomography in evaluation of formation of bone after grafting for repair of residual alveolar defects in patients with cleft lip and palate. Scand J Plast Reconstr Surg Hand Surg 39 : 15-21, 2005

30. Rosenstein SW, Long RE Jr, Dado DV, Vinson $\mathrm{B}$, Alder ME : Comparison of 2-D calculations from periapical and occlusal radiographs versus
3-D calculations from CAT scans in determining bone support for cleft-adjacent teeth following early alveolar bone grafts. Cleft Palate Craniofac J 34(3) : 199-205, 1997

31. Noguchi K, Hamada Y, Kondoh T, Iino M, Niitsu K, Ishii H, Sonoyama T, Kawarada T, Seto $\mathrm{K}$ : Clinical usefulness of dental X-ray computed tomography for postoperative assessment of secondary alveolar bone grafting. Jpn J Oral Maxillofac Surg 49(10) : 559-565, 2003 (in Japanese with English abstract)

32. Yamashiro T, Kubota Y, Tanaka T, Yoshizumi J, Ninomiya T, Yoshiura K, Shirasuna K : Application of dental x-ray computed tomography in the evaluation of the alveolar cleft form and bone formation after bone grafting. J Jpn Cleft Palate Assoc 30 : 236-241, 2005 (in Japanese with English abstract)

33. Oka H, Moriguchi T, Sato Y : Postoperative assessment of secondary bone grafting to the alveolar cleft using three-dimensional cone beam computed tomography. Jpn J Plast Surg 49(1) : 49-57, 2006 (in Japanese with English abstract) 